\title{
Intentional Learning as a Model for Philosophical Pedagogy
}

\author{
MICHAEL CHOLBI \\ California State Polytechnic University, Pomona
}

\begin{abstract}
The achievement of intentional learning is a powerful paradigm for the objectives and methods of the teaching of philosophy. This paradigm sees the objectives and methods of such teaching as based not simply on the mastery of content, but as rooted in attempts to shape the various affective and cognitive factors that influence students' learning efforts. The goals of such pedagogy is to foster an intentional learning orientation, one characterized by self-awareness, active monitoring of the learning process, and a desire for publicly certified expertise. I provide a number of examples of philosophyspecific teaching strategies that follow this paradigm.
\end{abstract}

Seasoned academics are understandably wary of trends in pedagogical theory. Such wariness has at least two origins, I suspect. First, new pedagogical theories are often developed at such a high level of generality that practitioners within a discipline may find it difficult to envision applying such theories to their own teaching. Philosophers, many of whom have strong disciplinary pride and allegiance, may doubt that any general theory of pedagogy could prove useful in teaching a discipline with somewhat idiosyncratic goals, methods, and content. Secondly, the healthy skepticism that characterizes academic life demands that new theories prove-or at least give strong evidence for-their usefulness before they are implemented.

Such skepticism is compounded by an understandable aversion to novel theories: For if these new theories are as revolutionary as they sometimes claim to be, then university and college instructors may view a seemingly untested theory as requiring greater personal transformation than they are willing to bear. Better to continue with the 'tried and true' (or at least the 'tried and not obviously deficient') than attempt a large-scale overhaul of one's teaching techniques and approach, an overhaul whose long-term benefits may not have been substantiated beforehand. Indeed, the literature on philosophy teaching reflects this 
aversion to comprehensive theoretical approaches in that it is dominated by practical tips about particular texts, courses, skills, and the like. As one scholar concluded after a review of recent articles on the teaching of philosophy, "one thing that is noticeable by its absence in the existing scholarship is theoretical reflection concerning the teaching of philosophy" (Sellars 2002: 118).

My aim here is to provide some systematic theoretical reflection on the teaching of philosophy, and more particularly, to suggest that despite these familiar concerns, a recent theoretical trend in higher education pedagogy, namely, intentional learning, is one that my fellow philosophers should embrace and advocate. The notion that institutions of higher education must be focused explicitly on student learning, rather than on teaching or the delivery of instruction per se, has been ascendant for over a decade (Barr and Tagg 1995, Tagg 2003). Indeed, many teaching-oriented colleges and universities have incorporated into their missions and strategic plans the goal of creating an institutional climate that focuses on substantive outcomes for student learning and how these outcomes may be measured, achieved, and refined over time. This move away from evaluating institutions of higher education solely in terms of 'inputs' (quality of student body, faculty achievement, financial resources, etc.) toward evaluation in terms of learning outputs reflects the public's understandable insistence that higher education be accountable in providing the social and personal goods it claims to provide, namely, the advanced knowledge and proficiencies students need in order to be productive employees or entrepreneurs, engaged and competent citizens, and reflective, mature human beings.

Nevertheless, the movement toward learning-based institutional paradigms lacks a parallel paradigm for classroom instruction. That is, there has been a great deal of discussion about the organizational deficiencies of colleges and universities with respect to promoting student learning and how these might be addressed, but relatively little about the specific teaching approaches, strategies, and goals that instructors ought to adopt so as to play their part in a learning-centered institution (Boggs 1999). My proposal here is that the concept of intentional learning can illuminate that role, especially for teachers of philosophy. In the most general sense, an intentional learning approach to pedagogy aims to produce intentional learners (sometimes called autonomous or self-directed learners). This is obviously an unsatisfactory characterization, so the first part of my discussion draws upon relevant learning research to outline the salient features of intentional learners and contrasts these with other "learning orientations." Learning orientations are the complex "conative, affective, and cognitive influences" that shape students' efforts to learn (Martinez 1998). A wide array of research suggests that such orientations play a significant 
role not only in the amount and depth of knowledge students acquire during their college educations, but also how favorably they evaluate their collegiate education experience (Martinez 1999).

After describing the learning orientation that characterizes intentional learners, I then outline how an intentional learning approach can be implemented, with specific reference to the teaching of philosophy. I proceed to outline five principles of pedagogical practice to be followed in order to guide students in becoming (more) intentional learners. These principles are drawn from the relevant scholarly literature on intentional learning, augmented by my own professional observation and experience. Teaching so as to produce intentional learners is obviously a major undertaking that cannot be fully captured in a handful of principles. Nevertheless, the five principles I identify are a good start, a foundation if you will, for the practices that philosophy instructors might follow should they opt for an intentional learning model for their teaching.

In my final section, I argue that philosophy teachers have good reason to welcome intentional learning as a pedagogical paradigm, in that this paradigm reflects the values and assumptions that philosophy teachers have traditionally brought to their craft. This is not to say that philosophy, as it presently taught in colleges and universities, universally conforms to the intentional learning model, or that philosophers have no work to do in striving to realize this model in their own teaching practices. Rather, intentional learning in fact represents the migration of typically philosophical modes of instruction to other disciplines. What the intentional learning approach therefore asks of the philosophy teaching community is not revolution but refinement.

\section{Learning Orientations and the Intentional Learner}

Neither a love of wisdom nor the good fortune to be blessed with the intellectual facility for its acquisition is individually sufficient to ensure that a person actually becomes wise. Any experienced philosophy teacher has encountered the student who readily masters the material and displays the abilities requisite to conduct philosophical inquiry but seems to exert only minimal effort. Similarly, any experienced philosophy teacher will recall the student with great enthusiasm for philosophical inquiry and an abiding desire to improve her knowledge and skills but who seems intellectually ill-equipped to do so. An exclusively cognitive approach to understanding how students learn enables us to explain the struggles of the latter student, but leaves us unable to explain the struggles of the former.

This realization, that learning results from an interplay of cognitive and attitudinal features, is central to the recent research on learning 
orientations (Snow and Farr 1987, Martinez 1998). Learning orientations are the sets of expectations, understandings, and emotional dispositions that students bring to their learning environment. (Learning orientations should therefore not be confused with 'learning styles' i.e., visual, auditory, kinesthetic, etc.) A student's learning orientation in turn shapes how she reacts to learning opportunities and how she makes numerous learning-related choices, including: what to learn, how to learn it, the level of effort to commit to learning, how to address obstacles to learning, and how to measure her progress or achievement (Martinez 1999).

An individual's learning orientation contains five elements:

[1] Learning beliefs: the student's beliefs about her level of knowledge or comprehension, her beliefs about the mechanisms or settings in which knowledge is acquired, her evaluation of her learning competencies, etc.

[2] Learning control: the student's attitudes about the degree of control or agency she has over her own learning choices and progress.

[3] Learning enjoyment: the extent to which the student welcomes or fears learning opportunities of various kinds.

[4] Learning effort: the amount and kind of strategies and performance efforts the student directs toward learning.

[5] Learning intentions: the goals or aims that the student associates with her learning efforts.

It is undeniable that whatever contribution native aptitude, prior academic preparation, or other social or environmental factors may have on student learning, students' learning orientations are a crucial variable in student learning success:

All learners approach learning with individual learning differences, some more successfully than others. Clearly, some learners have strong beliefs about learning and like to work hard, set high standards, achieve lofty goals, take risks, and use their initiative to discover and apply new information. In contrast, many learners remain satisfied with less effort, comfortable standards, highly structured environments, and easily attained goals. Other learners fall somewhere on the continuum between these two contrasting descriptions, and certainly some learners generally or situationally resist learning. (Martinez 1999: 13)

These variations in student learning orientation can be placed along the following continuum (Martinez 1998. For continuua organized along similar lines, see Perry 1970 and Clinchy 1990): At the bottom of this continuum are resistant learners. Resistant learners are indifferent or even hostile to academic learning, seeing it as useless in achieving their personal goals. They have had few positive learning experiences in the past and associate academic learning with boredom, alienation, and 
frustration. Pessimistic or apathetic, resistant learners see themselves as powerless, avoid nearly every learning opportunity, and are apt to define the goal of each such learning opportunity as mere survival. (Fortunately for university and college instructors, resistant learners are not likely to be a common sight within our classrooms.)

Next up on this continuum are conforming learners. These learners are generally very passive, content to accept knowledge, warehouse it, and reproduce it in order to meet others' expectations. In this regard, conforming learners may be caricatured as "bulimic learners" (Bain 2004: 40). They generally make little effort to deliberately engage with the content of what they are taught, preferring instead to let others control their learning and determine whether their efforts have been successful. Conforming learners generally do not deviate from their established learning procedures (which courses they take, their study habits, etc.), do not incorporate others' feedback into their subsequent learning efforts, and are averse to risk. Unsurprisingly then, they gravitate toward unambiguous standards, methodical learning techniques, and structured learning environments.

Above the conforming learners are the performing learners. Often motivated by external goals, such as grades, performing learners are task-oriented with short-term goals. Like conforming learners, they are averse to risk and rarely welcome intellectual challenges, but they will take a more deliberate or diagnostic approach to their own learning. They are frequently diligent and systematic, but wish to expend only the effort necessary to satisfy short-term external goals. Performing learners make use of an array of resources (the instructor, peers, campus tutors, etc.) and feel most comfortable in settings where the instructor's expertise can be readily accessed.

Finally, at the top of the continuum of learning orientations are the intentional learners. Highly self-aware, intentional learners enjoy meeting high standards and gain self-esteem from successes that follow upon persistent effort. They exercise significant responsibility and control over their learning efforts and are powerfully motivated by a desire for expertise that they subsequently share with others. Intentional learners have developed (or are concerned to develop) strategies for responding to academic challenge or adversity. These learners respond well to loosely structured but content-rich environments that emphasize problem solving.

In a nutshell, an intentional learning approach to pedagogy seeks to create intentional learners, or at the very least, move students further up this continuum toward becoming such learners. Why is this a basic and worthwhile teaching objective? First, from a merely self-interested standpoint, intentional learners make better students and better students make for more gratifying teaching experiences. The very language in 
the description of the intentional learner-expertise, motivated, responsibility, content-rich environments, etc.-resonates strongly with our most rewarding teaching experiences, those experiences in which learning is an intellectually robust experience for students and for the instructor. In the interaction between the committed instructor and the intentional learner, learning is not quite effortless, but is the happy byproduct of a "joint cognitive process" (Bereiter and Scardamalia 1989: 380) punctuated by discoveries, conundra, resolutions, and reconfigured understandings.

So much, then, to recommend an intentional learning approach to instructors. But what of students? Intentional learners exist, but (I imagine) they are the exception rather than the rule at most institutions of higher learning. In addition to a more enjoyable teaching experience for ourselves, the value of striving to transform our students into intentional learners is equally clear: The knowledge acquired by intentional learners is likely to be deeper, less transient, more available for application, more fully integrated, and more valued by the learner herself (Marton and Säljö 1976). The intentional learner not only achieves genuine mastery of wide swaths of knowledge, but is equipped to build upon this knowledge so as to extend and apply it in novel ways. Furthermore, because the learning of intentional learners results from intentional efforts in which they exercise their autonomy and self-awareness, intentional learners are likely to be motivated to keep learning.

At its best, an intentional learning approach aligns the various activities that comprise learning with the goal of learning itself.

We use the term intentional learning to refer to cognitive processes that have learning as a goal rather than an incidental outcome. All experience, we assume, can have learning as an incidental outcome, but only some cognitive activity is carried out according to procedures that contain learning goals. Whether intentional learning occurs is likely to depend on both situational and intrinsic factors - on what the situation affords in goal-attainment opportunities and on what the student's mental resources are for attaining those goals. (Bereiter and Scardamalia 1989: 363)

Resistant, conforming, and performing learners do learn. But whatever learning results in the absence of intentional learning strategies will be accidental, whereas intentional learners learn thanks to their explicit application of strategies whose purpose is the accumulation of knowledge, understanding, and insight. In this respect, intentional learning is metacognitive, directed not only at the content or subject matter, but also at the learning process itself. The bulk of "developmental research shows that successful learners have some kind of an awareness and conception of learning and show an understanding (to 
some degree) of how to use metacognitive and cognitive strategies and skills" (Brown 1987).

So described, the objective of advancing students' capacity for intentional learning may seem daunting, for students arrive in a college or university setting with well-established learning orientations, orientations that are likely as ingrained as Aristotelian moral character: Once inculcated by previous educational experiences, learning orientations are difficult to modify. The question, then, is which teaching strategies and approaches do this.

\section{Five Principles of Intentional Learning Instruction}

Teaching so as to enhance intentional learning demands conscientious attention to how in-class activities, assigned tasks, student evaluation, etc., contribute to or hinder intentional learning. But before directing one's attention to these matters, an instructor must have a grasp of two sets of objectives. The first are the objectives related to course content: the philosophical figures, theories, problems, proficiencies, etc., that students will be expected to master. The second are the objectives related to intentional learning: the skills, expectations, and attitudes toward learning itself that students are to develop. The relationship between the content objectives and the intentional learning objectives is complementary: The course content is a vehicle for the practice and development of intentional learning, and the intentional learning has the course content as its target object. Indeed, it is wrongheaded to suppose that before students can develop or exercise the skills associated with intentional learning (analysis, synthesis, evaluation, identification of new questions for investigation, etc.) they must master a set body of information to which these skills can be applied. Ideally, content mastery and improvement in learning orientations will take place concurrently (Bain 2004: 29).

Nevertheless, integrating these objectives may require instructors to reconceptualize the role of course content. Frequently, "strong allegiance to course content blocks the road" to intentional learning (Weimer 2002: 47). As philosophers, we may feel that our special expertise resides in our content knowledge, in our mastery of the philosophical skills, arguments, etc., that constitute our discipline. This tempts us to approach course and curriculum design solely in terms of content to be 'covered,' on the assumption that the more content covered in a course, the more students have learned and the more successful the course. But such an emphasis on content as the keystone of course and curriculum design often reinforces the passivity, anxiety, and lack of autonomy that characterizes learners at the lower rungs of the learning orientation continuum. Students accustomed to learning 
environments oriented exclusively around content mastery will adopt familiar learning strategies (e.g., memorization) that enable them to master the content in a superficial way, but do not help them understand or engage what they learn. (This outcome is most in evidence when students are asked to apply their knowledge to new items, as when a student who can recite the definition of deductive validity is flummoxed as to whether an argument she has not encountered before is in fact valid.) These strategies are efficient only insofar as they permit large volumes of material to be cursorily mastered. In contrast, an intentional learning approach tolerates paring back course content in most instances to allow the content to be mastered in intentional ways, even if this is more time-consuming.

Paring back course content may be perceived as a sacrifice of rigor or seriousness. But consider: Which student's knowledge reflects a more rigorous learning environment: the student who can recite in two sentences the difference between rationalist and empiricist theories of knowledge, or the student who can describe a priori and a posteriori knowledge; provide paradigmatic examples of each type; locate examples of such knowledge in historical and contemporary writings on epistemology; give arguments for the rationalist and empiricist positions; and relate each theory to various epistemic practices in the natural and social sciences? There are no guarantees that students whose learning orientation is intentional will achieve everything on the latter list. But it is a virtual certainty that students with less intentional learning orientations will achieve very little on the latter list.

My first intentional learning principle is therefore:

[1] Instruction must achieve an integration between learning objectives concerned with philosophical content and those objectives concerned with enhancing intentional learning aptitudes and attitudes. That is to say, instructors must attend not only to what is learned, but how it will be learned, and moreover, the 'how' must incorporate activities that develop the aptitudes and attitudes of intentional learning. The instructor is after all planning an inquiry into a set of problems (Finkel 2000: 54-55). Like any other deep-seated psychological disposition, intentional learning can only take root if practiced and reinforced. The philosophy instructor must therefore be willing to reduce course content (reading fewer figures, considering fewer theories, etc.) in exchange for the enrichment of intentional learning capabilities. Furthermore, as the instructor prepares lectures, discussions, written assignments, etc., she should be mindful not only of how these are directed at content mastery but also at the practice of intentional learning.

For example, in-class discussion is a common teaching tool in philosophy. But it is a tool whose utility in producing intentional 
learners requires careful consideration of both its content- and learning orientation-based goals. Two particular challenges stand out here. First, students often do not appreciate what learning goals are served by in-class discussion and what role their participation plays in meeting these goals (Kelley 1999). In a recent introduction to philosophy class, dominated by first-year students, I asked whether their secondary school teachers had used in-class discussion. Much to my surprise, less than a quarter raised their hands. This illustrates that discussion is for many students a novel pedagogical practice, and even for those students more experienced with it, they may be uncertain as to how it advances their learning. Students may wrongly assume that the aim of discussion is to enable the smartest and most well-prepared students to show off, or to have the instructor lead (or perhaps manipulate in a pseudo-Socratic sense) the students into the correct conclusions, or to score 'participation points.' Second, instructors are often not sufficiently intentional about the use of discussion. Nearly all smaller philosophy courses make use of discussion, whether spontaneous or pre-planned, but how often do we ask ourselves about the learning goals of a particular episode of in-class discussion? Is the purpose of the discussion to identify the salient features of a philosophical theory? To analyze its logical implications? To compare or evaluate rival theories or claims? To help students place their own views within the logical space of possible theories? To apply theories or claims to more familiar phenomena? In the absence of such forethought, many students, especially the conforming and performing learners, may see in-class discussion as aimless, as failing to tell them what they most desire to know: what the instructor knows and what the instructor expects them to know (Redfield 2000). When instructors lack a clear sense of the learning goals associated with discussion, this in turn sends encoded messages about what discussion is for, messages that students will filter through their existing learning orientations in ways that hamper learning and (probably) discourage participation in discussion. Being intentional about the learning aims of discussion need not mean quashing impromptu discussion, stimulated by student questions and comments. But whether or not discussion is planned or impromptu, the instructor must ask not only what philosophical learning goals it serves but also the underlying picture of learning that students will absorb from in-class discussion. Furthermore, instructors must help students see that discussion can advance learning. For example, after an in-class discussion, the instructor might ask the students to write in their notes the three most important conclusions gleaned from the discussion, or to write the question raised in discussion that needs further attention from the class, etc. Such retrospective exercises enable students to 
begin seeing discussion as purposeful inquiry rather than a showcase for verbal eloquence, a contrived venue for debate, etc.

As this examination of discussion illustrates, honoring this first principle obviously requires a good deal of anticipation on our part. So too with the second principle:

[2] Instruction must provide opportunities for the diagnosis of students' learning orientations, especially as they apply to philosophy as a discipline. The learning orientations students bring to their study of philosophy contain elements pertaining to learning in general and to the learning of philosophy in particular. For the overwhelming majority of students, their first college or university philosophy class is their first exposure to philosophy, a fact that 'triggers' various elements of their learning orientations. These include beliefs about their abilities at reading, writing, or note-taking; their past experiences in studying history, literature, or other humanistic disciplines with a strong textual focus; beliefs about philosophers and philosophy itself; the rigor of the humanities compared to other genera of academic disciplines; and the relationship between philosophy and their stated career goals. Taken together, these aspects of students' learning orientations will strongly determine their success and satisfaction in studying philosophy.

Instructors must therefore identify (and help students identify) those components of students' learning orientations that are most likely to be triggered by the study of philosophy. "Educators should diagnose learning orientation and apply this information to differentiate the audience before planning, designing, developing, implementing, delivering, and evaluating instruction" (Martinez 1999: 74). The value of such identification for instructors is that it enables them to know more about the expectations their students have about their learning experiences, along with the likely obstacles to learning generated by their learning orientations. For students, being cognizant of their learning orientations is a first step toward the metacognitive stance of intentional learners (Bain 2004: 160). In order to be intentional learners, students must direct their efforts not only at mastering substantive knowledge, but also at themselves and the methods (appropriate or not) they utilize to gain such knowledge. Many students will feel threatened and resist being asked to scrutinize their learning orientations (Weimer 2002: 151-53). Nevertheless, the diagnosis of learning orientation, especially the discipline-specific aspects of these orientations, is crucial to students experiencing intellectual empowerment and exerting more agency over their learning, both of which are essential to students learning intentionally.

How should instructors approach the diagnosis of learning orientations? Both instructors and students have crucial roles to play. Instructors take the lead role when they investigate student performance on 
various tasks for evidence of the attitudes and aptitudes that contribute to or hinder intentional learning. E.g., student writing is an important window on learning orientation. In student essays, we find evidence, direct or indirect, about their self-understanding as learners (how much effort they will willingly put forth, their level of intellectual engagement, the degree to which they write to their audience's expectations or standards, their tolerance for risky interpretations or positions, their concern for articulation and development of philosophical problems rather than quick identification of answers, etc.). A useful exercise is for the instructor to take a representative batch of student essays (it need not include every essay in the class, only 5-10, say) and 'write herself a memo' about one aspect of student learning orientation implicated in the essays. For example, I have found it valuable to collect a group of essays and ask myself to 'fill in the blank' for each: "The student understood the goal of this essay to be ." In one such exercise, the blanks were filled by concepts of widely varying content, such as "to write in Descartes's style," "to show Descartes is not only mistaken, but dumb," "to reorganize material from class lectures, book report-style," "to link Descartes's philosophy to the politics of the 1600s," "to defend Descartes's claim that knowledge requires certainty." My own answers suggest the wide variation of learning orientations my students manifested in this one assignment. Students clearly had different expectations and aspirations for the writing task I had given them, most of which varied from those I had for the assignment in question.

The second avenue for learning orientation diagnosis is selfdiagnosis by students. As Maryellen Weimer notes, "the ability to evaluate one's own work accurately and constructively does not develop automatically," (Weimer 2002: 124), and faculty can stimulate this ability simply by asking students to reflect on their own performance:

Faculty should not be the only ones doing assessment work. It is yet another way we make students dependent learners. When students hand in a paper, ask them if it is a good paper and see what they say. Mine are confused when I ask the question and counter with these typical responses: "Why are you asking me?" "How would I know?" "You're the one who'll decide that."

So if intentional learning is to take root, students must systematically interrogate their own knowledge and the manifestations thereof. Instructors can facilitate this self-diagnosis through a variety of methods, including the use of entry or exit surveys, or pre- and post-tests (administered at the beginning and the end of a class meeting, or at the beginning and the end of a course) (Kelley 1999); the submission of self-assessments on particular assignments or for the quarter as a whole; or as part of students' evaluation of courses or faculty. Instructors must craft student self-assessment activities carefully in order to 
ensure that students take them seriously and that students understand the criteria the instructors desire them to utilize in assessing their own efforts and progress. One especially fruitful example of self-assessment is what I have come to call "imagine next term." At the end of the term, I ask students (in conjunction with a final examination, term paper, etc.) to imagine what we might study in a "part II" of the course just concluded: which problems or questions need further consideration, which texts needed more detailed treatment, which learning methods (essays, lectures, discussion, etc.) should be emphasized, which topics follow naturally on the course content, etc. I do not expect students to produce a detailed hypothetical syllabus, but the exercise compels them to take an intentional stance toward their learning, as students attempt to catalog what they have already learned, what they should have learned (but may not have), what they desire to learn in light of their learning, and how their learning influences future inquiry and future learning.

Some instructors may fear that students will take advantage of opportunities for self-assessment to flatter themselves in order to improve their grades or their standing in the eyes of the instructor. Assuredly, some students will. Yet this is a reflection of their own immaturity as learners and their own inexperience with intentional learning. Because students are rarely accustomed to self-diagnosis or self-assessment, early results will likely be disappointing: vacuous, fumbling, tinged with anxiety or resentment (Bain 2004: 45). An instructor must therefore convey that efforts at learning orientation diagnosis and assessment are not frivolous 'icing' on the cake of content but rather an integral and mandatory part of the course. Eventually, though perhaps not under the tutelage of the same instructor, students develop an appreciation for the greater autonomy that such diagnosis and assessment affords them, along with the greater respect it displays for their own learning capacities.

Nor should we fear that integrating student self-assessment into the process of developing intentional learning habits is an abdication of the instructor's responsibility to establish and 'enforce' performance standards. As I shall suggest in my discussion of the third principle below, an intentional learning approach demands an unorthodox understanding of the purpose of evaluating student performance. But permitting students to self-assess helps students to describe and critique the link between their own learning efforts and evaluative standards, a link that is often opaque to conforming or performing learners who tend to dissociate learning from grading or evaluation or to see their relationship as entirely arbitrary. Indeed, when students are unsure about what they are supposed to be learning, and lack the intentional learning outlook to perceive how they might go about learning it, performance anxiety 
(as well as a continuous trickle of complaints and questions regarding grading) is likely to result. An intentional learning approach reattaches these by forging a learning partnership between the instructor and the students (or in the case of peer assessment, partnerships among student peers) wherein instructors devise evaluative standards and guide students' intentional efforts to meet those standards. Failure to give students the opportunity to self-assess their learning efforts and progress removes the intentionality from their own learning efforts and returns it to the instructor, precisely where it cannot be if intentional learning habits are to bear fruit. Self-assessment thus encourages the student to self-teach, a method likely to produce deeper and more durable knowledge (Bain 2004: 27-29).

Most importantly, students asked to self-diagnose and self-assess are exercising the very metacognition that intentional learners exercise as matter of second nature. The result is often a form of metacognitive dissonance, in which what students think they know, what students believe about their own learning, etc., does not align with their own performance. This is a crucial early step in catalyzing greater learner motivation, autonomy and control.

As this discussion of learning orientation indicates, an intentional learning approach also modifies the role of student evaluation:

[3] Instruction must integrate summative and formative evaluation so as to model intentional learning. Traditionally, student evaluation has been largely summative: Instructors use examinations, papers, etc., as tools to measure what students know (or have come to know.) Insofar as evaluating student achievement is an institutional prerogative, this approach to evaluation is reasonable. However, it nurtures a static, linear, and incremental view of knowledge, in which students master small chunks of knowledge and then set that knowledge aside, as if these chunks formed an unconnected heap. Every instructor knows that learning is a cumulative affair, but a good many of our usual evaluative tools and techniques do not take adequate stock of this fact.

An intentional learning pedagogy therefore asks that we use evaluation that is both summative (or backward-looking) and formative (or forward-looking). That is, evaluative tools should, both individually and collectively, foster students' mindfulness in attending to their own learning processes, instead of focusing on the 'bottom line' of grades. Rather than closing the book on each chapter of students' learning, instruments of evaluation should point the way to the next chapter by assisting students to engage in the reflective process of self-diagnosis described under principle [2].

The practical task for the instructor is to utilize evaluation instruments and practices that deflect student attention from the evaluative product (the exam, paper, etc.) in question toward the process that 
generated that product. Consider: How often do the very same students exhibit the same problematic tendencies in their written work without remedying them? As instructors, we must use the evaluation of students as an opportunity to help them see these problematic patterns and begin to make intentional efforts to address them. Similarly, exams can be used as a teaching tool. Not only can instructors use pre-exam review sessions as opportunities for student self-diagnosis, but they can follow exams with discussions of common student misunderstandings. The point here is not simply to catalog student mistakes, but for students to figure out what in their learning efforts led to these mistakes. Suppose, e.g., that an exam asked students to sort a group of statements according to whether a utilitarian or a Kantian moral theorist would agree with each statement. Instructors should not simply inform students of the correct answers, but also collaborate with students to ferret out why common mistakes occurred. An intentional learning approach thus necessitates careful attention to the evaluative instruments we use, the feedback we give in association with these instruments, and the implicit messages these instruments send to students about learning. Such attention will encourage the picture of learning as an autonomous and goal-directed activity, instead of something that simply happens (Bereiter and Scardamalia 1989: 371-72).

[4] Instruction must aim at highly specific learning objectives against which students can positively gauge their progress. Purely summative evaluation of students also works against students' ability to partition their learning efforts into a series of tasks toward which they can make significant progress. For students at the lower ends of the learning orientation continuum, the relationship between their learning efforts and learning itself is often opaque. Hence, students have difficulty analyzing their own learning performances, identifying their specific strengths and weaknesses, formulating strategies for improvement, etc. While cynicism about students' willingness to learn is understandable, the absence of student motivation can also be traced to their prior frustrations with learning environments that deny them the opportunity to bring intentionality to their learning efforts. When students do not fully understand what is to be learned, how the performance of various learning tasks measures and fosters that learning, and how they can manage their efforts in order to learn effectively, the likely results are disorientation, resentment, and a sense of bewilderment at the whole learning enterprise. In particular, students may come to see their learning efforts as controlled by objectives that are arbitrary, ill-defined, or under constant revision. Rather than a sense of purposefulness, security, and growing mastery governing students' learning efforts, they are instead characterized by anxiety, aimlessness, and risk aversion. 
In philosophy, where learning objectives are likely to be defined less by knowledge of fact or theory than by command of a body of inquiry and of investigative techniques, the threat of such student frustration and disengagement is acute. As one philosophy instructor has written:

Because the consumer mentality of many of our students conditions them to see value in terms of tangibility and immediacy, and because philosophical issues do not admit of easy and/or determinate answers, philosophy seems to them unworthy of attention. Students must be shown that it is not the expectation of coming to a resolution of a philosophical issue that makes that issue important, but rather that in thinking through an issue, we learn an immense amount about our current values, principles, and beliefs, and perhaps also about the values, principles, and beliefs that it is worthwhile having. We must show students that even if we cannot come to a final conclusion on some philosophical issue, the process of analyzing the issue can teach them much about themselves and where they stand. (Kelley 1999)

A central task for the philosophy instructor seeking to help students be more intentional learners is therefore to specify learning objectives that allow students to gauge their progress in meeting larger learning goals. In particular, these objectives must be more provisional than they might be in other disciplines, couched not so much in terms of successful resolution of a philosophical question, but in terms of identifying central disagreements, strengths and weaknesses of competing positions, etc.

Consider the writing of essays, perhaps the most complex task we ask students to perform, as it involves (typically) the interpretation of philosophical texts, the analysis of philosophical claims and arguments, the synthesis and evaluation of these claims and arguments, and the organization of all this into a coherent and communicatively effective written work. For performing and conforming learners, the writing task can be especially daunting when approached en masse, as a single, amorphous cognitive undertaking. What such students require is not only guidance from instructors as to how to impose structure on the writing task, but also feedback and reinforcement that is responsive to that structure. "Writing a good philosophy paper" is in fact several tasks aimed at a common end, but how is the student who receives a $\mathrm{B}$ and three sentences of written feedback on an essay in a position to see her overall performance as the product of several 'subroutines' toward which she will direct her future efforts? Detailed feedback, especially on pre-final writing products, is essential to help students appreciate where they should devote their energies. Such feedback also encourages students as they make progress, often slow but cumulative, toward larger learning objectives. I am not simply suggesting that we follow the common adage that all feedback to students should contain 
something positive. It should. But more than this, student feedback should reinforce their progress in such a way that students come to see that their own learning demands ongoing problem-solving on their part, problem-solving that encompasses not only the identification of problematic areas of student performance but also the strategizing of how to remedy those areas.

Providing detailed analytic feedback, crafted with specific learning objectives in mind, also makes possible something that students rarely provide themselves: permission to fail. I have found that if instructors challenge their students to meet specific learning objectives and provide them the frequent and precise feedback needed for them to accurately gauge their progress toward those objectives, then students will commit themselves to these objectives to such an extent that that they will be willing to take cognitive and intellectual risks when pursuing these objectives. Risk aversion is of course the corollary of an abnegation of student responsibility; the student who neither knows what she is attempting to learn or how she ought attempt to learn it will quickly place the responsibility for learning back on the instructor. The learning that results in such a relationship is likely to be superficial and painfully acquired.

More concretely, how do we go about communicating these learning goals and reinforcing them to students? With respect to student writing, a scoring rubric used for all writing assignments allows students to see that philosophical writing, regardless of its topic should strive for certain values (clarity of expression, analytical acuity, accurate and sympathetic interpretation of texts, logical persuasiveness, etc.). Such rubrics are also useful in another strategy, giving students ample opportunities to improve their work (Bain 2004: 36). Academic calendar prerogatives require us to impose deadlines on student efforts. But notice again how such deadlines reinforce the idea that learning results from a heap of jumbled and disconnected tasks that, once completed, bear no relation to larger learning goals. And if a student genuinely desires to improve her performance, why should we use deadlines that function as disincentives to do this? I have adopted in several of my courses the policy that students may revise any of their written work (and thereby improve their grades) so long as their revised work reaches me at least one day prior to the day I must submit grades. Granted, only a handful of students - those whose learning habits are already fairly intentional - take advantage of this policy. And certainly fixed deadlines spur students to produce work of whatever quality. Yet I cannot see the wisdom in removing incentives that allow students who are sincerely motivated by a desire to learn (and to provide evidence of that learning) to continue to pursue that learning. A task deadline should not be treated as a learning deadline. 
More controversially, I oppose the use of grading curves. Curves send the implicit message that it is not progress toward meeting learning goals that counts. In fact, it is not learning per se that counts. Instead, what matters is how much one has learned relative to one's peers. But grading on a curve thereby devalues the learning objectives themselves. Some students who thrive on competition may be motivated by a curve. But then we should ask whether performing better than one's peers in meeting goals that one does not find worth pursuing is a healthy message to send students, as if outdoing others, regardless of the merits of the task in which one outdoes others, is a worthwhile goal. A curve also gives the mistaken impression that collaboration is inimical to learning success.

The larger point here is that governing our teaching practices (course design, feedback, etc.) in terms of specific learning objectives demystifies the process of learning for students, a process which, thanks to the fundamentally investigative nature of philosophy, is likely to be especially nebulous to students. Such demystification is a crucial step in creating the conditions under which students will begin to engage their learning as intentional learners.

[5] Instruction must enable the motivating relevance of philosophical material to be discovered or illustrated, not dictated. Because philosophy is an unfamiliar discipline to most students, as instructors we feel a natural yearning to justify our discipline (and our students' decision to study it) by pointing to its relevance to concerns students already have. Such a yearning is laudable, in that ample research suggests that students learn most successfully when they confront problems they see as "intriguing, beautiful, or important" (Bain 2004: 57). Confronting such problems not only makes for a more enjoyable learning experience, but will tend to stimulate the effort, confidence, and sense of cumulative mastery found in intentional learners. Students will more actively manage their learning when it focuses on tasks they perceive as personally meaningful or urgent in some way (McCombs 1994). The learning that results from a self-motivated embrace of philosophical problems will also prove more durable, for as Plato observed (Republic, book VII), "knowledge acquired under compulsion obtains no hold on the mind."

Nevertheless, there exists a danger lurking within the otherwise commendable desire that students see the study of philosophical problems as relevant to their own concerns. The danger is that attempts to explain to students how a philosophical problem is relevant to their existing concerns will backfire and in fact diminish learning. An intentional learning approach demands that learners come to formulate their own learning goals and develop their own internal reasons that drive their inquiry. What is therefore needed is for students to discover the rel- 
evance of philosophical problems to their own concerns. How can an instructor create a learning environment that permits students to discover (and articulate) this relevance for themselves? Consider how the philosophical problem of free will is often introduced to students: We point out how assumptions about freedom and responsibility underlie our penal practices, our efforts to persuade others, our invocations of reactive attitudes, etc. But my own perception is that while a fraction of students will be moved to investigate the problem on the basis of such abstract concerns, most will not.

In order to remedy this motivational deficit, we must follow the dictum "know what thy students know." Regrettably, it is difficult to underestimate the gaps in social and factual knowledge that students bring to our classrooms, gaps that undermine their ability to appreciate the significance of philosophical problems. This became apparent to me in recent Introduction to Philosophy courses. I had decided to teach the ethics of privacy in the course, on the assumption that "net generation" students, accustomed to clicking through privacy policies on the Internet, would find the topic urgent and familiar. Initially, however, student interest was low. I then distributed a survey to students about their knowledge and attitudes about privacy, and the results shocked me. Few students bothered to read the privacy policies they were subject to, only a third knew that most credit card issuers sell personal information to third parties, and almost none knew that the university had a privacy policy, much the less the content of that policy. My in-class discussions of privacy had fallen on deaf ears because the students had simply not been aware that the ethics of privacy was something more than an abstract or futuristic worry, but one in which they were already intimately enmeshed as consumers and as students.

In keeping with our earlier emphasis on learning diagnosis (principle [2]), such informal gathering of student knowledge can assist our efforts at connecting philosophical problems to student concerns. A second strategy is to remind ourselves of the limitations of the instructor's role as an authority figure, a role which complicates our efforts to help students appreciate the value of philosophical inquiry. Because many students, especially those at the lower ends of the learning orientation continuum, view instructors as authority figures who quasi-mechanically transmit their knowledge to students, instructors' describing to students the importance of what they are studying will not be well received. Instructors can tell students what to know or what counts as knowledge, but not why to know it, and on the whole, it is very difficult to tell someone what intellectual problems to care about in the hope that she will be moved to investigate such problems. Such attempts to impose relevance on students ("here's why you should 
care") run counter to the very autonomy and self-direction we aim to instill.

This suggests that students may be better motivated to investigate a philosophical problem if the problem is illustrated by a figure who is neither presented nor understood as a philosophical authority. Our training as philosophers generally enables us to rationally navigate a philosophical problem, but we are not trained to vividly convey the significance of those problems, even when they galvanize us personally. Fortunately, a panoply of creative works (films, novels, television, etc.) exists to fulfill this function. I would suggest that the best creative works for philosophical pedagogy are those that cause students to vicariously experience a philosophical problem. Students who view Vanilla Sky temporarily occupy the position of the film's main character, thereby 'living' Cartesian radical skepticism. Similarly, students reading Orwell's Animal Farm, Lem's Solaris, or Golding's Lord of the Flies are immersed, respectively, in the possibility of a slowly emerging totalitarianism, the blurring of self/other boundaries, and the descent into the brutality of the state of nature. Doubtless, creative works can be valuable in many disciplines, but I would argue that they serve an especially vital function in philosophy, where one of the discipline's goals is to dissect and question ordinary beliefs, often by way of thought experiments or other counterfactual imaginings. Students are already culturally primed to imaginatively suspend disbelief when cued to do so by films, novels, etc., hence they do not typically react to these experiences as being artificial or contrived, as even the most well crafted philosophical hypotheticals are.

Granted, even the best such creative works should not be confused with rigorous philosophical treatises. Yet they can serve to help students see the need for such treatises and the systematic reflection that produced them. Again, these works do not tell students what matters. There is a vast distance between identifying a philosophical problem and identifying with it. Creative works help make the latter possible, a motivation crucial to students being willing to expend their intellectual efforts on examining the problem. Furthermore, the authors of these works do not perform in them, in the way that the philosophy instructor performs when trying to persuade students that philosophical problems are worth exploring. The student is thus persuaded to take a philosophical problem seriously without the direct manipulation of the instructor and feels that the problem is to a large extent her original discovery. What results is that the student feels a greater sense of control of her own learning and a more intimate attachment with the philosophical problems in question.

These five principles can serve to guide teachers of philosophy as they strive to promote intentional learning among their students. As 
students successfully implement their own learning strategies, they begin to causally attribute these successes not to luck, the instructor's skills, etc., but to their own efforts (Weiner 1972: 208). In the end, following these principles will result in a virtuous loop, in which motivated students actively pursue their self-identified goals rooted in learning, develop personal strategies to meet these goals, experience gratification at meeting these, and then proceed to formulate new learning goals (Schunk 1991). This is perhaps the most fundamental benefit of an intentional learning approach: At its best, it stimulates students to make learning, not some other objective extrinsic to the learning process, the chief motivation for their learning efforts (Dweck 1986, Bain 2004: 32-36). This in turn enhances the students' sense of the educational process not as manipulative, but as one over which they exert significant control. Pedagogy organized in accordance with these five principles can thus lead resistant, conforming, and performing learners to develop the learning-positive attitudes and aptitudes of their more intentional peers. (For a similar set of principles, see Bain 2004: 108-09.)

\section{The Philosophical Roots of Intentional Learning}

I hope to have done enough thus far to, first, indicate the power of intentional learning as an organizing concept for philosophical pedagogy, and second, provide at least the beginnings of a set of general principles for implementing this concept effectively. Nevertheless, I expect that some philosophers will shrug off my suggestions, not because they are misguided but because they are old news. That is, many philosophers will recognize in intentional learning a fairly familiar set of instructional goals and methods. To a great extent, this is correct, for the increased attention now directed at intentional learning may be seen as the migration of the characteristic values and concerns that have traditionally informed the teaching of philosophy. Here I conclude with several affinities between intentional learning pedagogy and these traditional values and concerns.

First, intentional learning approaches recognize what philosophers have always understood: that knowledge has an internal structure. (Much of the traditional debate within philosophical epistemology has focused on what that structure is.) Intentional learning brings to the forefront that genuine learning requires mastery not of a series of discrete facts or claims, but also the synthesis of these facts and claims and a concomitant understanding of their logical and evidentiary interrelations. The notion of intentional learning reminds us that because bodies of knowledge have internal structures, a central goal of teaching must be to enable students to replicate these structures within their 
cognitive psychology, including even the lacunae, tensions, or limitations within these bodies of knowledge.

Second, intentional learning conveys to learners that knowledge has a history, both in their own case and in general. It helps students appreciate, by virtue of the challenges they experience in transforming themselves into intentional learners, the messiness, misdirection, and discontinuity that often accompanies bona fide learning. The intentional learner is thus in a position to understand that even the most established bodies of knowledge come to exist only thanks to numerous contingencies, a point often emphasized in recent historicist philosophies of sciences.

Next, intentional learning pedagogy accentuates the features of Socratic modes of inquiry. In particular, this pedagogy underscores that new knowledge grows from gaps in students' existing knowledge, or even from their outright ignorance. Bereiter and Scardamalia, in the first scholarly article I am aware of that utilizes the phrase 'intentional learning,' state that "knowing what one does not know is a vital part of intentional learning" (Bereiter and Scardamalia 1989: 375). Intentional learning thus embraces the Socratic notion that learning often presupposes the "unlearning" of what one thought one knew, in preparation for the acquisition of new and deeper knowledge.

In various ways, then, intentional learning conceives of students as epistemologists, not only of the content they study, but of themselves. In simultaneously pursuing content knowledge and metaknowledge (i.e., knowledge about their own state of knowledge), intentional learners act not only as investigators of particular domains, but as reflexive epistemologists who subject their own knowledge to continuing scrutiny. The study of philosophy is especially well-suited to help students develop this dual focus. It has often been observed that philosophy, in contrast to nearly every other academic discipline, is not defined by its subject matter. As Simon Blackburn has noted, other disciplines provide us lenses through which the world may be understood, but only in philosophy is the lens itself the object of study (Blackburn 1999: 5). The overall effect of this dual focus is not only deeper knowledge, but an expanded sense of the "learning goals one can envision" (Bereiter and Scardamalia 1989: 373). Moreover, when intentional learners learn, it results from sustained inquiry. This should be comforting to philosophers, for one of the facets of philosophy that students initially find a source of bewilderment is its relative absence of uncontroversial 'fact.' Philosophy is all questions, no answers, it is sometimes said. In this regard, philosophy and intentional learning are such a natural fit that it seems hard to envision how authentic philosophical learning could fail to be intentional. 
Furthermore, intentional learning approaches coincide with many of the humanistic ethical values that have traditionally informed philosophical pedagogy. First, the Platonic view that knowledge is both extrinsically and intrinsically valuable finds clear expression in the notion of intentional learning. An intentional learning approach assigns external incentives such as grades their proper place, namely, as measures of learning, not as the goal of students' learning efforts. Moreover, in encouraging students to become metacognitive self-evaluators, an intentional learning approach aims to facilitate students' internalization of learning as the goal of their academic activities.

An intentional learning approach also embodies respect for the individual student as a learner. By permitting learners the latitude to develop their own epistemic self-understandings, such an approach respects the learner as an autonomous agent capable of a good deal more than superficial mastery of philosophical material. This is not to say that an intentional learning approach leaves out the instructor's role. Indeed, enhancing intentional learning requires the instructor to perform the role of Socratic midwife, but with two progeny: philosophical knowledge, acquired by intentional investigation and inquiry, and the dispositions and attitudes of intentional learners. Helping students become more intentional learners is a matter of establishing a partnership. We have all heard the cliché "I'll pretend to teach and you pretend to learn." Intentional learning gives the lie to this pretense, insisting that genuine learning can never occur under so long as it remains unacknowledged and unchallenged.

Yet at the same time that intentional learning-based pedagogy fosters individual autonomy, it also creates partnerships among students and instructors that serve as the basis for an authentic community of intellectual inquiry. Students (and instructors) motivated by a genuine desire to traverse a path of inquiry together will energize one another, and an authentic intellectual community emerges when the "energy that drives the course flows from the students' real need to investigate the question they hold in common" (Finkel 2000: 68).

In describing the habits of the best college teachers, Ken Bain writes that though such teachers taught within their disciplines, they did so

in the context of focusing on the intellectual, and often ethical, emotional, and artistic, development of their students. Indeed, rather than thinking in terms of teaching history, biology, chemistry, or other topics, they talked about teaching students to understand, apply, analyze, synthesize, and evaluate evidence or conclusions. They stressed the ability to make judgments, to weigh evidence, and to think about one's own thinking. . . . 'I want my students to understand what we think we know in this field,' one scientist explained, 'but I also hope they will understand how we reached those conclusions and how those findings are subject to ongoing inquiry.' (Bain 2004: 46) 
I propose that this expresses the attitude of the instructor striving to create intentional learners, and that in this description philosophers should see a mirror of their own extant pedagogical assumptions. The move toward intentional learning pedagogy can therefore be seen as a migration of the methods, concerns, and values of philosophical instruction to the rest of the academy. That being said, this is no justification for complacency among philosophers. As my earlier principles illustrate, adopting an intentional learning approach to pedagogy may necessitate dramatically revising our curricula, our use of evaluative tools, our assumptions about students, and our understanding of the student-instructor relationship. After all, what we say about how we teach and how we teach do not necessarily align. But above all else, creating intentional learners means becoming more intentional teachers, teachers who take a systematic and scholarly stance toward the production of student learning (Boyer 1997, Bain 2004: 175). Just as intentional learners take risks and exercise responsibility for their own learning goals and efforts, so too must their instructors, if their partnership is to prove ultimately effective.

\section{Note}

I gratefully acknowledge the comments and suggestions of David Adams, Don St. Hilaire, Jim Manley, Judy Miles, Peter Ross, Laurie Shrage, and Zuoyue Wang in developing this article.

\section{Bibliography}

Bain, K. 2004. What the Best College Teachers Do. Cambridge, Mass.: Harvard University Press.

Barr, R., and J. Tagg. 1995. "From Teaching to Learning: A New Paradigm for Undergraduate Education." Change 27: 12-25.

Bereiter, C., and M. Scardamalia. 1989. "Intentional Learning as a Goal of Instruction." In Knowing, Learning, and Instruction: Essays in Honor of Robert Glaser, ed. L. B. Resnick. Hillsdale, N.J.: Erlbaum Associates.

Blackburn, S. 1999. Think: A Compelling Introduction to Philosophy. Oxford: Oxford University Press.

Boggs, G. R. 1999. "What the Learning Paradigm Means for Faculty." AAHE Bulletin 51: 3-5.

Boyer, E. 1997. Scholarship Reconsidered. New York: Jossey-Bass.

Brown, A. 1987. "Metacognition, Executive Control, Self-Regulation, and other More Mysterious Mechanisms." In Metacognition, Motivation, and Understanding, ed. F. Weinert and R. Kluwe. Hillsdale, N.J.: Erlbaum Associates, 65-116.

Clinchy, B. M. 1990. "Issues of Gender in Teaching and Learning." Journal of Excellence in College Teaching 1: 52-67.

Dweck, C. S. 1986. "Motivational Processes Affecting Learning." American Psychologist 41: 1040-48.

Finkel, D. L. 2000. Teaching with Your Mouth Shut. Portsmouth, N.H.: Boynton/Cook. 
Kelley, A. 1999. "Coping with the Consumer Mentality When Teaching Introductory Philosophy." APA Newsletter on Teaching Philosophy 99:1.

Martinez, M. A. 1998. "Executive Summary of the Learning Orientation Research.” Expert Learning Community, McKay School of Education, Brigham Young University. . 1999. "An Investigation into Successful Learning Measuring the Impact of Learning Orientation, a Primary Learner-Difference Variable, on Learning." Ph.D. Dissertation, Department of Instructional Psychology and Technology, Brigham Young University.

Marton, F., and R. Säljö. 1976. "On Qualitative Differences in Learning—2: Outcome as a Function of the Learner's Conception of the Task.” British Journal of Educational Psychology 46: 115-27.

McCombs, B. 1994. "Strategies for Assessing and Enhancing Motivation: Keys to Promoting Self-Regulated Learning and Performance." In Motivation: Theory and Research, ed. H. F. O'Neil, Jr., and M. Drillings. Hillsdale, N.J.: Erlbaum, 49-69.

Perry, W. G. 1970. Forms of Intellectual and Ethical Development in the College Years: A Scheme. New York: Holt, Rinehart, and Winston.

Redfield, J. 2000. "On Discussion Teaching." In Teaching at Chicago: A Collection of Readings and Practical Advice for Beginning Teachers. Center for Teaching and Learning, University of Chicago. http://teaching.uchicago.edu/tutorial/discussion .shtml, January 25, 2007.

Schunk, D. 1991. "Self-Eefficacy and Academic Motivation." Educational Psychologist 26: $207-31$.

Sellars, J. 2002. "Some Reflections on Recent Philosophy Teaching Scholarship.” PRSLTSN Journal 2: 110-27.

Snow, R., and M. Farr. 1987. "Cognitive-Conative-Affective Processes in Aptitude, Learning, and Instruction: An Introduction." In Conative and Affective Process Analysis, ed. R. Snow and M. Farr. Hillsdale, N.J.: Erlbaum Associates.

Tagg, J. 2003. The Learning College Paradigm. Bolton, Mass.: Anker Publishing.

Weimer, M. 2002. Learner-Centered Teaching: Five Key Changes to Practice. San Francisco: Jossey-Bass.

Weiner, R. 1972. "Attribution Theory, Achievement Motivation, and the Educational Process." Review of Educational Research 42: 203-15.

Michael Cholbi, Department of Philosophy, California State Polytechnic University, Pomona, Pomona, CA 91768; mjcholbi@csupomona.edu 